\title{
Percepção do racismo no Rio de Janeiro ${ }^{*}$
}

Cloves Luiz Pereira Oliveira

Paula Cristina da Silva Barreto

\section{Resumo}

Analisa os resultados de uma pesquisa de opinião realizada pelo Centro de Articulação de Populações Marginalizadas (CEAP) e Núcleo de Pesquisas, Informações e Políticas Públicas da Universidade Federal Fluminense (DATAUFF), de 28 de janeiro a 13 de abril de 2000, sobre relações raciais no Rio de Janeiro. A partir daí, aponta as limitações de uma abordagem individualista do racismo, as dificuldades enfrentadas por pesquisas empíricas voltadas para a mensuração do preconceito racial, e sugere alguns temas que poderiam ser incluídos na agenda dos estudos sobre o racismo no Brasil. Um conjunto amplo de temas foi investigado pelo CEAP-DATAUFF, buscando não somente mensurar o preconceito racial no Rio de Janeiro, mas também abordando outros temas presentes na atual agenda de debate sobre relações raciais no Brasil, tais como: identidade racial, percepção sobre os determinantes da situação do negro no Brasil, desigualdade racial, casamento inter-racial, mestiçagem, voto étnico, outros preconceitos na sociedade contra pobres, favelados, mulheres, nordestinos e homossexuais, aspirações sociais segundo raça, posicionamento da população fluminense frente às propostas de implantação de políticas de ação afirmativa.

Palavras-chave: racismo, populações marginalizadas, relações raciais, situação do negro, desigualdade racial, casamento inter-racial, voto étnico, políticas de ação afirmativa.

\footnotetext{
* Agradecemos a Marcelo Simas, doutorando em Ciência Política do Iuperj, pelas orientaçôes sobre o tratamento estatístico utilizado neste trabalho. Convém, no entanto, destacar que são de nossa inteira responsabilidade as análises contidas neste artigo.
} 


\begin{abstract}
Perception of racism in Rio de Janeiro

It analyzes the results of an opinion poll carried out by the Population Rehabilitation Center for the Underprivileged - CEAP, and by the Research, Information and Public Politics Center from the Fluminense Federal University (DATAUFF). During the period of January $28^{\text {th }}$ and April $13^{\text {th }} 2000$, people were asked about racial relationships in Rio de Janeiro. The text points out the limitation of an individualistic approach of racism, the difficulties faced by empirical researches in terms of measuring racial prejudice, and suggests some themes that could have been included in the study about racism in Brazil. A research was done by the CEAP-DATAUFF about several themes, in order to not only measure the racial prejudice in Rio de Janeiro, but also to bring to light other themes that are recently discussed, such as: racial identity, perception of the determiners of the Negro situation in Brazil, racial inequality, inter-racial marriages, race-mixing, ethnic vote, other social prejudices against poor people, people from the favelas, women, people from the northeast (nordestinos), homosexuals, social aspirations by race, the fluminenses' understanding of proposals to implement an affirmative action politics.
\end{abstract}

Keywords: Racism, underprivileged population, racial relations, Negro situation, racial inequality, inter-racial marriage, ethnic vote, affirmative action policy.

\title{
Résumé
}

\section{Perception du racisme à Rio de Janeiro}

On analyse dans cet article les résultats d'une enquête sur les relations raciales à Rio de Janeiro, réalisée par de Centre d'Articulation des Populations Marginalisées - CEAP et par le Département de Recherches, Informations et Politiques Publiques de l'Université Fédérale Fluminense - DataUFF, du 28 janvier au 13 avrie 2000. C'est à partir de cela que nous montrons les limitations d'un abordage individualiste du racisme, les difficultés rencontrées dans des recherches empiriques visant la mensuration du préjugé racial et l'on suggère quelques sujets qui pourraient être inclus à l'agenda des études sur le racisme au Brésil, comme par exemple: identité raciale, perception des 
déterminants de la situation du Noir au Brésil, inégalité raciale, mariages inter-éthniques, vote éthnique et autres préjugés de la société contre les pauvres, les femmes, les gens du nord-est et les homossexuels, les aspirations sociales selon la race, la prise de position de la population de l'état de Rio de Janeiro par rapport aux propositions pour le mise en place de politiques d'action affirmative.

Mots-clés: racisme, populations marginalisées, relations raciales, situation du Noir, inégalité raciale, mariages inter-éthniques, vote éthnique, politiques d'action affirmative. 


\section{Introdução}

\footnotetext{
$\mathrm{E}$
} ste artigo analisa os resultados de uma pesquisa de opinião realizada pelo Centro de Articulação de Populações Marginalizadas (CEAP) e Núcleo de Pesquisas, Informações e Políticas Públicas da Universidade Federal Fluminense (DATAUFF), de 28 de janeiro a 13 de abril de 2000, sobre relaçôes raciais no Rio de Janeiro. A partir daí, aponta as limitações de uma abordagem individualista do racismo, as dificuldades enfrentadas por pesquisas empíricas voltadas para a mensuração do preconceito racial, e sugere alguns temas que poderiam ser incluídos na agenda dos estudos sobre o racismo no Brasil.

A pesquisa CEAP-DATAUFF se constituiu numa ampla pesquisa domiciliar realizada em todo o Estado do Rio de Janeiro, distribuída nas regióes amostrais do município do Rio de Janeiro, região metropolitana e interior do estado, perfazendo um total de 1.172 entrevistas. Deste total de entrevistados, 48,2\% eram homens e $51,8 \%$ eram mulheres. A amostra era composta por $34,5 \%$ de pardos, seguida por $27,4 \%$ de brancos, $26,7 \%$ de pretos, $2,7 \%$ de amarelos e 8,8\% de indígenas. ' Quanto ao grau de instrução dos entrevistados, $19,6 \%$ eram analfabetos ou possuíam o primário incompleto, $29,2 \%$ possuíam o primário completo ou o $1^{\circ}$ Grau incompleto; $21,5 \%$ possuíam $1^{\circ}$ Grau completo ou o $2^{\circ}$ Grau incompleto; $24,5 \%$ possuíam o $2^{\circ}$ Grau completo ou o Superior incompleto, apenas 5,2\% Superior completo.

Um conjunto amplo de temas foi investigado pelo CEAP-DATAUFF, buscando não somente mensurar o preconceito racial no Rio de Janeiro, mas também abordando outros temas presentes na atual agenda de debate sobre relaçóes raciais no Brasil, tais como: identidade racial, percepção sobre os determinantes da situação do negro no Brasil, desigualdade racial, casamento inter-racial, mestiçagem, voto étnico, outros preconceitos na sociedade contra pobres, favelados, mulheres, nordestinos e homosse- 
xuais, aspirações sociais segundo raça e posicionamento da população fluminense frente às propostas de implantação de políticas de ação afirmativa.

Seria impossível tratar de todos estes temas no escopo deste trabalho e em vista disso selecionamos alguns tópicos que consideramos importantes no debate atual sobre o racismo no Brasil. $\mathrm{O}$ primeiro deles trata da identificação do preconceito racial existente na população: foram incluídas perguntas no questionário, provavelmente, com essa finalidade, e como estratégia de análise das respostas oferecidas a essas perguntas optamos por construir um índice de preconceito racial. Como mostraremos adiante, os resultados parecem indicar que, em geral, o preconceito racial é baixo ou inexistente na população do Estado do Rio de Janeiro. O otimismo dessa conclusão é deslocado se notarmos que quando se trata da percepção da existência do racismo, os resultados são completamente distintos: a análise das respostas oferecidas mostra que, em geral, existe uma alta percepção da existência do racismo na sociedade. Antes de dar continuidade à análise desses resultados, vale ressaltar que na identificação do preconceito racial o que está em questão é a maneira como os indivíduos vêem a si mesmos, enquanto na análise da percepção do racismo é o modo como os indivíduos vêem a sociedade em geral. Esse descompasso entre a autopercepção - via de regra como um indivíduo sem preconceito racial - e a percepção acerca da sociedade - onde se reconhece que existe racismo - já foi objeto de análise em outras pesquisas sobre as atitudes raciais no Brasil, mas continua sendo uma questão mal compreendida ou não resolvida (Schwarcz, 1996; Turra \& Venturi, 1995).

Cabe destacar que nesse texto nos propomos a analisar uma parte do banco de dados resultante da pesquisa CEAP-DATAUFF, mas não participamos da formulação das perguntas e da preparação do questionário. Portanto, ao recorrermos à construção dos índices de preconceito racial e de percepção do racismo enfrentamos o desafio de selecionar perguntas para compor tais índices que não foram incluídas no questionário com esta finalidade. Lançamos mão de tal estratégia de análise dos resultados da pesquisa com o objetivo de tecer algumas considerações críticas em relação à abordagem do racismo que durante décadas tem utilizado definições operacionais focalizadas exclusivamente nas atitudes e atos individuais, o que contribuiu decisivamente para a popularização de definiçōes que fazem referência imediata ao preconceito e à discriminação quando se trata de refletir sobre o racismo. O contraponto 
disso é a dificuldade persistente de pensar o racismo como associado às relações de poder e à desigualdade (e dissociado do ódio), o que tem impactos diretos sobre o apoio da população às políticas visando à promoção da igualdade racial no Brasil.

Ao longo desse texto discutiremos inicialmente alguns tópicos relacionados às definição e identificação do preconceito racial, analisando os resultados para as perguntas consideradas isoladamente e como parte do indice de preconceito racial. Em seguida, discutiremos as questóes relacionadas com a percepção do racismo, novamente analisando as perguntas isoladamente e como parte do indice de percepção do racismo. Mais adiante veremos como esses resultados se alteram quando incluímos na análise algumas variáveis sócio-demográficas importantes (como cor, gênero, idade e grau de instrução) e tratamos das preferências da população em termos de estratégias anti-racistas (como as políticas compensatórias). Na conclusão, discutiremos algumas questóes suscitadas ao longo da apresentação dos resultados.

\section{Preconceito, discriminação e desigualdade racial no Brasil}

Desde os anos 1930 o preconceito e a discriminação raciais têm sido objetos de análise dos cientistas sociais, especialmente para pensar seus impactos na dinâmica das relações sociais em sociedades multirraciais e multiétnicas, marcadas por desigualdades raciais e representações negativas contra um ou mais grupos, como por exemplo: o preconceito contra os afrodescendentes nos Estados Unidos e no Brasil. Segundo Jones, o "preconceito é uma atitude negativa, com relação a um grupo ou pessoa, baseando-se num processo de comparação social em que o grupo do indivíduo é considerado como o ponto positivo de referência" (1973:3). Tal atitude negativa seria necessária para que houvesse algum referente positivo para comparação, sendo que o julgamento negativo e prévio dos membros de uma raça, uma religião ou dos ocupantes de qualquer outro papel significativo, seria mantido apesar de fatos que o contradiriam.

De acordo com Jones, o interesse pela investigação sobre o preconceito constituiu o campo dos estudos sobre as atitudes raciais, estimulando cientistas sociais e psicólogos a produzirem definições operacionais do conceito. Um dos primeiros resultados desse esforço conduziu à definição hoje considerada clássica (ou tradicional) segundo a qual a presença de estereótipos e de distância so- 
cial eram os principais indicadores do preconceito racial. O estudo dos estereótipos foi uma das primeiras incursões experimentais feitas pelos psicólogos sociais no estudo do preconceito durante os anos 1930, especialmente aqueles inspirados nos trabalhos da Escola de Chicago. Em termos empíricos, isto se traduziu na realização de pesquisas com base em entrevistas que estimulavam os entrevistados a julgar/opinar sobre os estereótipos regularmente atribuídos aos vários grupos da sociedade, e se posicionar sobre a distância social em relação a indivíduos pertencentes a estes grupos.

Na década de 1950, tendo em vista o holocausto, bem como as reflexôes sobre os horrores que o ódio racial podem causar numa sociedade, os pesquisadores sobre relações raciais passaram a se preocupar não apenas em mensurar o preconceito racial mas, sobretudo, em descobrir estratégias para combatê-lo. Neste cenário, o Brasil aparecia como um objeto de estudo interessante, uma vez que, diferente do que acontecia nos Estados Unidos, na África do Sul e alguns países europeus, era visto como um país onde parecia existir um "paraíso racial". Durante as décadas de 1940, 1950 e 1960 foram realizados no Brasil os primeiros estudos sobre o preconceito racial e, segundo Guimarães, "os estudiosos observaram a distância social entre brancos e negros, medida pela escala de Bogardus, recolheram ditos e ditados racistas, observaram limites na interação entre brancos e negros, documentaram as dificuldades de ascensão social experimentadas por pretos e mulatos" (1999:90), em regióes diferentes do país. ${ }^{2}$ Os resultados de algumas destas pesquisas evidenciaram que existia um abismo entre as posições normativas, de adesão aos valores igualitários, aceitos pela maioria dos entrevistados e as posições quanto à aplicação prática desses princípios. Isso ficou evidenciado na recusa à maior proximidade social, demonstrada nas respostas sobre comportamento hipotético, por exemplo, na situação de casamento: a maioria esmagadora dos entrevistados afirmava que não casaria com "negro" ou "mulato" (Bastide, 1956; Bastide \& Van Den Berghe, 1957). Os autores consideraram um paradoxo que existisse adesão às normas democráticas, isto é, aceitação da igualdade de oportunidades para "negros" e "brancos", e que, por outro lado, fosse alto o grau de estereotipia negativa e de segregação nas relações pessoais, e que houvesse uma adesão quase total à endogamia. Essa ambivalência, para eles, constituía o "dilema brasileiro".

Este conjunto de investigações contribuiu para a maior visibilização da existência do preconceito racial e forneceu subsídios 
para as denúncias da democracia racial brasileira como um mito. Um dos mais importantes estudos nesta áea foi realizado por Florestan Fernandes e Roger Bastide em São Paulo, como parte do ciclo da UNESCO. Fernandes concluiu que os brasileiros não evitavam, mas tinham vergonha de ter preconceito, e o fato de que se considerava "feio" admitir a discriminação e não o ato de discriminar se explicava pelo "preconceito de não ter preconceito". Nesta forma particular de racismo, que Fernandes (1972) chamava também de "preconceito retroativo", não se mostrava ou não se falava sobre algo que se reconhecia existir, as hierarquias ficavam cristalizadas e intocadas enquanto na aparência o que se mostrava era a amabilidade. Bastide destacou que o fato de não existirem manifestações abertas de preconceito racial, e do fator racial ser disfarçado pelo fator classe, se explicava pela interferência do mito da democracia racial. Em vista disso, as barreiras encontradas pelo negro eram dissimuladas por um verdadeiro ritual de polidez amável que acentuava em lugar de fazer desaparecer a distância social (Bastide \& Fernandes, 1959). Oracy Nogueira inovou ao defender que no Brasil existia um tipo diferente de preconceito racial -o "preconceito de marca" - que não se confundia com o tipo de preconceito racial dos Estados Unidos - o "preconceito de origem". Segundo ele, o preconceito de marca não implicava "uma exclusão ou segregação incondicional dos membros do grupo discriminado, e sim uma preterição dos mesmos quando em competição, em igualdade de outras condições, com indivíduos do grupo discriminador" (Nogueira, 1998:243). Nogueira mostrou que no Brasil "a cor branca facilita a ascensão social, porém não a garante por si mesma; de outro lado, a cor escura implica antes uma preterição social que uma exclusão incondicional de seu portador" (ibidem:167).

Rompendo com a teorização que era utilizada nessa época nos Estados Unidos, estes autores rejeitaram o modelo que considerava o preconceito racial como um fenômeno individual e de fundo psicológico, ocasionado pelo ódio e pela ignorância, e que seria distinto da discriminação racial; esta, sim, vista como manifestação do racismo. Estes autores afirmaram que o preconceito racial não poderia ser dissociado das relações de dominação existentes entre os grupos presentes na sociedade brasileira. Essa trilha interpretativa foi seguida por inúmeros pesquisadores que ao longo das décadas de 1980 e 1990 documentaram a existência de desigualdades raciais no Brasil. ${ }^{4}$ 
No entanto, a grande preocupação dos estudos realizados entre os anos 1940 e 1960 com a identificação do preconceito e da discriminação raciais, compartilhada por organizações anti-racistas voltadas para a denúncia da democracia racial como um mito, contribuiu para que se popularizasse uma concepção do racismo restrita à dimensão individual. Apesar disso, a constante divulgação dos resultados de pesquisas que comprovam que as desigualdades raciais são persistentes no Brasil, seja por iniciativa de organizações anti-racistas, de órgãos oficiais ou dos meios de comunicação, ao longo das décadas de 1980 e 1990, bem como a implementação de projetos e políticas de ação afirmativa, a partir da segunda metade da década de 1990 , têm tido como resultado a crescente visibilidade de outra concepção do racismo associada à estrutura desigual de acesso às oportunidades. Certamente, estas mudanças irão repercutir na agenda das pesquisas sobre as atitudes raciais, com a tendência que estas deixem de se limitar ao estudo dos temas que preocuparam os estudos clássicos - como a identificação do preconceito e da discriminação -, passando a incluir outros temas importantes como os distintos modos de percepção do racismo, as explanações para a desigualdade, as preferências em termos de políticas anti-racistas e as explanações para tais preferências. Tais mudanças são coerentes com o lugar central que a desigualdade racial tem ocupado no debate atual sobre o racismo e, principalmente, sobre o anti-acismo na sociedade brasileira.

\section{O preconceito racial no Estado do Rio de Janeiro}

Algumas perguntas que foram incluídas no questionário utilizado na pesquisa realizada pelo CEAP-DATAUFF no Rio de Janeiro testaram a adesão dos entrevistados às definições estereotipadas dos negros e o desejo de manutenção de distância social, e é com base nas respostas oferecidas a essas perguntas que faremos algumas afirmações acerca do grau de preconceito racial da população fluminense identificado nessa pesquisa. Além disso, analisaremos as respostas dadas à pergunta direta sobre a admissão do preconceito racial por parte dos indivíduos.

Quanto aos estereótipos, os resultados mostraram que, em sua maior parte, os entrevistados discordaram daquelas afirmaçōes que revelavam associações explicitamente negativas aos negros, como podemos verificar nos seguintes exemplos: 
P18 - Os negros são menos esforçados do que os brancos. . 86,6\% discordaram totalmente ou em parte; . 13,4\% concordaram totalmente ou em parte;

P48 - Tem poucos negros na política porque: 1) os negros não gostam de politica; 2) existe preconceito contra os negros;

3) os negros não têm capacidade para fazer política.

. 92,6\% escolheram as opçôes 1 ou 2;

. 7,4\% escolheram a opção 3 ;

P56.1 - Negros não têm capacidade para Medicina, Odontologia, etc.

. $92,2 \%$ discordaram totalmente ou em parte;

. $7,8 \%$ concordaram totalmente ou em parte;

P56.3 - Negros não gostam de Medicina, Odontologia porque pedem esforço maior nos estudos.

. $80,9 \%$ discordaram totalmente ou em parte;

. $19,1 \%$ concordaram totalmente ou em parte.

Quanto à distância social o resultado foi semelhante, ou seja, a maioria dos entrevistados mostrou-se favorável à aproximação social com os negros, como se pode observar nos resultados para a seguinte pergunta:

P32 - Você se importaria de ter um chefe negro: 1) sim 2) não 9) NS/NR.

. 96,7\% responderam não;

$.3,3 \%$ responderam sim.

A admissão do preconceito racial foi testada através da seguinte pergunta:

P58 - Vocêse considera, em relação aos negros, uma pessoa que: 1) Não tem nenhum preconceito de cor 2) Tem um pouco

3) Tem muito.

. $87,5 \%$ dos entrevistados escolheram a opção 1 ; $.12,5 \%$ escolheram as opções 2 ou 3.

Evidencia-se aqui que a maioria dos entrevistados se considera isenta de preconceito racial e tem uma auto-avaliação bastante positiva em relação a essa questão, e esse resultado é coerente com as respostas que foram oferecidas às perguntas sobre estereótipos e distância social.

Uma última questão poderia ser acrescida a esse conjunto e trata da legislação anti-racista em vigor: 
P29: Pena de 1 a 3 anos para crimes de racismo: 1) Dura demais; 2) Justa; 3) Leve; 9) NS/NR.

$.83,1 \%$ consideraram a pena prevista na lei em vigor justa ou leve;

$.16,9 \%$ a consideraram dura demais.

Tomando estas seis perguntas como itens para compor um índice de preconceito racial, temos um resultado que é, no mínimo, curioso para aqueles que estudam e denunciam o racismo brasileiro. Utilizando uma escala de cinco (5) pontos, que vai do mínimo (0) até o máximo (5), temos que:

Tabela 1

\begin{tabular}{c|c|c}
\multicolumn{2}{c}{ Distribuição do índice de preconceito } \\
\hline $\begin{array}{c}\text { Índice de } \\
\text { preconceito }\end{array}$ & $\mathrm{N}$ & $\%$ \\
\hline 0 & 734 & 62,7 \\
\hline 1 & 247 & 21,1 \\
\hline 2 & 125 & 10,6 \\
\hline 3 & 49 & 4,1 \\
\hline 4 & 7 & 0,6 \\
\hline 5 & 10 & 0,9 \\
\hline Total & 1172 & 100,0 \\
\hline
\end{tabular}

Analisando a Tabela 1 observamos que não há uma distribuição equilibrada de respostas, sendo que $62,7 \%$ dos entrevistados se mostraram totalmente isentos de preconceito racial. Diante desse resultado consideramos que seria inadequado até mesmo levar adiante a análise, apresentando cruzamentos com algumas variáveis sócio-demográficas, pois quaisquer interpretaçôes que desenvolvêssemos estariam apoiadas em bases muito frágeis e sujeitas, portanto, a distorçôes.

Como interpretar um resultado como esse, principalmente, se levarmos em conta que as desigualdades raciais existem e têm aumentado nas duas últimas décadas, e que a estigmatização racial - seja através dos insultos, piadas ou representações negativamente estereotipadas - continua presente no cotidiano dos brasileiros? Tal resultado convida antes de tudo à reflexão sobre o tipo de instrumento utilizado na pesquisa - o questionário -, o modo como este foi construído - a escolha dos temas e a formulação das perguntas -, e a estratégia de análise que utilizamos. Em relação a esse último ponto, caberia perguntar se não chegaríamos a outra conclusão caso tivéssemos construído o índice de preconceito racial de 
outra forma, ou seja, utilizando itens diferentes daqueles que escolhemos, ou recorrendo ao uso de outros materiais de apoio. Provavelmente sim, mas o problema principal ao nosso ver não está na construção de uma medida melhor ou mais refinada do preconceito racial, embora sejam válidas as iniciativas feitas nesta direção, como a pesquisa realizada por Almeida, Young \& Pinto no Município do Rio de Janeiro (2002). Em outras palavras, é preciso levar em conta que existem formas distintas de estigmatização com base na idéia de raça, mais ou menos verbalizadas, mais ou menos explícitas, e que variam de um contexto para outro, e as estratégias de análise quantitativa que têm sido mais utilizadas nos surveys atitudinais talvez sejam mais adequadas para o estudo da estigmatização quando esta ocorre de forma explícita e direta.

No caso brasileiro é sabido que a etiqueta de relações raciais vigente na sociedade desaprova as manifestações flagrantes de estigmatização com base em distinçôes de cor. Neste sentido, seria mesmo de se esperar que não houvesse concordância da maior parte da população com frases explicitamente racistas como as que foram incluídas no questionário utilizado nessa pesquisa. ${ }^{5}$ Esta dificuldade de obter comprovação através de pesquisas empíricas da existência de estigmatização racial tem sido encontrada até mesmo em países como os Estados Unidos, onde a segregação chegou a ser legalmente sancionada e eram comuns os insultos verbais e, até mesmo, as agressões físicas contra os descendentes de africanos. Nas pesquisas realizadas recentemente sobre as atitudes raciais neste país é cada vez maior a discordância da população com frases que expressam estereótipos negativos associados aos negros, ao tempo que tem crescido também o apoio ao fim da segregação racial que continua existindo informalmente. ${ }^{6}$ Não queremos, com isto, dizer que os descendentes de africanos deixaram de ser vistos e representados de modo negativamente estereotipado, seja no Brasil ou nos Estados Unidos, mas que a população tem demonstrado ter conhecimento de que é socialmente reprovável fazê-lo, e isto se reflete na escolha das opções de resposta apresentadas em surveys como o que foi realizado pelo CEAP-DATAUFF. Embora seja impossível afirmar que estas atitudes individuais se refletirão em comportamentos não discriminatórios contra os indivíduos que aparentam ter ascendência africana, é digno de nota que os entrevistados buscam se mostrar afinados com os valores anti-racistas que têm sido difundidos na sociedade, tentando evitar parecer que são racistas, fatos que não ocorriam há algumas décadas atrás. 
Outro aspecto a considerar é que as relações sociais no Brasil são predominantemente vividas (e interpretadas) sob o prisma das relações de classe e interpessoais. Uma evidência disso é que na pesquisa CEAP-DATAUFF a proporção daqueles que admitem que já se sentiram discriminados por condição financeira (31\%) é quase o dobro da proporção dos que afirmam que já se sentiram discriminados por sua cor ou raça (16\%), e o triplo da proporção dos que já se sentiram discriminados por questóes de gênero $(10,8 \%){ }^{7}$ Outra evidência nessa direção é que quando se trata de atribuições para as desigualdades raciais existe um senso comum bastante arraigado em torno da idéia de que o fator explicativo mais importante é o econômico. Através de uma pesquisa de caráter etnográfico, realizada numa cidade do interior do Estado do Rio de Janeiro, Twine (1998) analisou os argumentos utilizados para explicar a desigualdade racial, recorrendo à estratégia de perguntar aos moradores como se explicaria o fato de a elite da cidade ser "branca", e, segundo os resultados, de várias formas a desigualdade racial foi negada. $\mathrm{O}$ argumento de classe foi o mais citado, ora associado à escravidão, ora relacionado à exploração de classe e à reestruturação econômica. Em outra pesquisa realizada entre estudantes universitários da cidade de São Paulo, chegamos a resultados semelhantes no que diz respeito à utilização mais freqüente dos argumentos econômicos como justificativa para as desvantagens educacionais dos negros, especificamente, no acesso ao ensino superior (Barreto, 2003).

Como já foi dito, os resultados das pesquisas realizadas no Brasil nas décadas de 1940 e 1950 mostraram que os entrevistados não se mostravam constrangidos em afirmar os estereótipos negativos em relação aos negros, pois estes eram revelados nas entrevistas que foram realizadas em várias regióes do país. Os resultados obtidos em pesquisas recentes, como esta que foi realizada no Rio de Janeiro, mostram que ocorreram mudanças significativas nesse cenário. $\mathrm{Na}$ pesquisa de alcance nacional realizada pelo Instituto Datafolha, em 1995, e que teve como objetivo principal mensurar o preconceito racial existente no Brasil, a conclusão foi que apenas uma pequena parcela da população revelava ter um grau alto de preconceito racial e que a maioria apresentava um grau baixo ou médio. Estes dados levaram os responsáveis pela pesquisa a afirmar que no Brasil existia o "racismo cordial" (Turra \& Venturi, 1995).

É digno de nota que outra pesquisa recente realizada no município do Rio de Janeiro apresenta resultados divergentes, ou seja, segundo os autores foi possível revelar que o preconceito de cor é 
forte e bem arraigado (Almeida et alii, 2002). Neste caso, o uso de fotos foi associado às perguntas formuladas pelos pesquisadores, sendo possível avaliar com mais precisão como as atribuições variam com o gradiente de cor.

\section{A percepção do racismo}

O fato de que a percepção do racismo esteja sendo objeto de estudo no Brasil se reveste de maior importância diante da tradição que marcou o período da década de 1930 até a década de 1970 de não colocar em discurso a questão do racismo, algo que era parte da posição anti-racialista que se tornou quase oficial nesse período. O próprio fato de que estejam sendo realizadas pesquisas que fazem a população falar ou produzir discursos sobre o racismo no Brasil indica que existem mudanças em curso na regra tácita que recomendava não falar sobre esse assunto, pelo menos em público e fora dos espaços reservados da casa. Em suma, embora o racismo ainda possa ser considerado um tema sensível no Brasil, não há dúvida de que tem se criado uma corrente de opinião pública em torno do tema, fato que se deve, entre outras coisas, às mobilizações lideradas por organizações anti-racistas que surgiram nas duas últimas décadas do século passado.

Para fins de análise dessa questão vamos considerar que o reconhecimento de que os negros em geral são objeto de preconceito e/ou discriminação racial indica que há percepção do racismo. Isto significa dizer que é necessário que haja, por um lado, reconhecimento da existência de estereótipos negativos associados aos negros e de mecanismos de manutenção da distância social dos brancos em relação aos negros, e, por outro lado, que estes encontram barreiras à ascensão social e recebem tratamento diferenciado na sociedade brasileira. Vamos analisar os resultados para um conjunto de perguntas que abordaram esses temas e que consideramos adequadas para compor um indice de percepção do racismo.

Para testar a crença na democracia racial, selecionamos as seguintes perguntas:

P14 - Acha que no Brasil os negros e os brancos: 1) Convivem bem; 2) Existem alguns problemas de convivência; 3) Existem muitos problemas de convivência

. 78,6\% escolheram as opções 2 ou 3;

. 21,4\% escolheram a opção 1 . 
P18D - A discriminação racial impede que os negros consigam bons empregos e melhorem de vida: 1) concordo muito; 2) concordo pouco; 3) discordo pouco; 4) discordo muito.

$.82,2 \%$ escolheram as opçóes 1 ou 2 ; $.17,8 \%$ escolheram as opções 3 ou 4 .

P47.3 - Ser negro para um candidato que quer se eleger: 1) Atrapalha muito; 2) Atrapalha um pouco; 3) Não atrapalha.

$.60,9 \%$ escolheram as opções 1 ou 2 ;

$.39,1 \%$ escolheram a opção 3.

A percepção sobre a existência do preconceito e discriminação foi tratada, ainda, através de pergunta direta, como a seguinte:

P8.3 - O Preconceito contra negros. 1) Muito; 2) Pouco; 3) Nenhum.

. 74,1\% escolheram a opção 1 ;

. 25,9\% escolheram as opções 2 ou 3.

P 56.4 - O sistema educacional discrimina os negros: 1) concordo muito; 2) concordo pouco; 3) discordo pouco; 4) discordo muito.

. 58,4\% escolheram as opções 1 ou 2 ;

. 41,6\% escolheram as opçóes 3 ou 4.

A pergunta seguinte testou o reconhecimento de que existem estereótipos negativos associados aos negros:

P48 - Tem poucos negros na política porque: 1) Os negros não gostam de politica; 2) Existe preconceito contra os negros; 3) Os negros não têm capacidade de fazer politica.

. $77,5 \%$ dos entrevistados escolheram a opção 2 ;

. $22,5 \%$ escolheram as opções 1 e 3 .

Sobre a distância social, selecionamos as seguintes perguntas:

P31 - Quanto a ter um chefe negro a maioria das pessoas: 1) Se importaria com isso; 2) Não daria importância para a cor do seu chefe.

$.51,7 \%$ escolheram a opção 1 ;

. 48,3\% escolheram a opção 2 . 
P33 - Se um parente próximo casasse com uma pessoa negra, a maioria das pessoas brancas: 1) Não se importaria com isso; 2) Não gostaria.

. $60,5 \%$ escolheram a opção 2 ;

. 39,5\% escolheram a opção 1 .

Tomando estas oito perguntas como itens para compor um índice de percepção do racismo, temos um resultado bastante diferente daquele obtido no índice anterior, com uma distribuição das respostas muito mais equilibrada e com um amplo reconhecimento da população do Estado do Rio de Janeiro quanto à existência de racismo contra os negros (94\%). Dentro de uma escala de zero (0) a oito (8), onde zero representa nenhuma percepção do racismo e oito representa o máximo de percepção do racismo, temos a seguinte distribuição:

Tabela 2

Distribuição do índice de percepção do

\begin{tabular}{c|c|c}
\multicolumn{3}{c}{ racismo } \\
\hline $\begin{array}{c}\text { Índice de percep̧ão } \\
\text { do preconceito }\end{array}$ & $\mathrm{N}$ & $\%$ \\
\hline 0 & 33 & 2,8 \\
\hline 1 & 37 & 3,2 \\
\hline 2 & 64 & 5,5 \\
\hline 3 & 112 & 9,6 \\
\hline 4 & 147 & 12,5 \\
\hline 5 & 193 & 16,5 \\
\hline 6 & 222 & 18,9 \\
\hline 7 & 213 & 18,1 \\
\hline 8 & 151 & 12,9 \\
\hline Total & 1172 & 100,0 \\
\hline
\end{tabular}

Considerando que de 0 a 2 pontos existe baixa percepção do racismo, de 3 a 5 pontos média percepção e de 6 a 8 pontos alta percepção, temos a seguinte distribuição:

Tabela 3

Distribuição do Índice de percepção de racismo (alta, média e baixa)

\begin{tabular}{l|c|c}
\hline $\begin{array}{c}\text { Índice de percepção do } \\
\text { preconceito }\end{array}$ & $\mathrm{N}$ & $\%$ \\
\hline Alta (6-8) & 586 & 49,9 \\
\hline Média (3-5) & 452 & 38,6 \\
\hline Baixa $(0-2)$ & 134 & 11,5 \\
\hline Total & 1172 & 100,0 \\
\hline
\end{tabular}


O próximo passo na análise é identificar como varia a percepção do racismo de acordo com a cor, gênero, grau de instrução e idade. De maneira geral, observamos que são os negros, as mulheres, os jovens e as pessoas com instrução de nível médio que o fazem com maior intensidade. ${ }^{8}$

Em relação à cor, conforme exposto nas Tabelas 4 e 5 , o que se observa é que existe um gradiente de percepção do racismo que acompanha o gradiente de cor, de maneira que se considerarmos o subgrupo formado por aqueles que têm alta percepção do racismo vemos que é maior a proporção de "pretos", seguidos de perto por "pardos" e "indígenas", vindo então os "amarelos" e, por último, os "brancos". Isto significa que, quanto mais "escuro" o indivíduo, maiores são as chances de ele identificar a existência de racismo no Brasil. De modo inverso, considerando aqueles que têm baixa percepção do racismo, é maior a proporção de "brancos", seguido por "pardos", "indígenas" e, por último, os "pretos”. Vale ressaltar que, embora não exista uma oposição total entre a percepção de "brancos" e "negros" (considerando aqui o resultado do somatório de "pretos" e "pardos"), a cor é uma variável que interfere na intensidade com que o racismo é percebido. Em outras palavras, "brancos" e "negros" têm percepções distintas, mas não opostas, do racismo. Além disso, existem graus de percepção distintos também entre os "negros", ou seja, os "pretos" apontam existir mais racismo do que os "pardos". Este resultado pode ser explicado pelas próprias características do racismo brasileiro que, sem excluir todos os negros em todas as situações, pretere alguns deles em determinadas situações e sob certas condições. A maior percepção do racismo entre os negros que apresentam características físicas africanas mais evidentes ocorre, provavelmente, porque eles o experimentam com mais intensidade no cotidiano, ou porque há maior reconhecimento, entre eles, de que este é um problema que afeta o grupo. No caso dos brancos, a menor percepção do racismo pode estar ligada ao fato de que eles se sentem, com mais freqüência, numa sociedade racialmente neutra ou imaginam que este é um problema que afeta menos os negros.'

As Tabelas 6 e 7 mostram que as mulheres têm uma percepção mais aguçada do racismo que os homens, sobretudo as mulheres negras, reforçando a idéia que a percepção da existência do racismo parece ser mediada pela perspectiva de gênero. É provável que a maior convivência com as vicissitudes impostas pelo sexismo e racismo nas suas relações de trabalho, convívio social e poder, 
Tabela 4

Índice de percepção do racismo, segundo a cor (\%)

\begin{tabular}{c|c|c|c|c|c}
\hline $\begin{array}{c}\text { Índice de percepção } \\
\text { de preconceito }\end{array}$ & Amarelo & Branco & Indígena & Pardo & Preto \\
\hline 0 & & 3,8 & 2,0 & 4,5 & 0,7 \\
\hline 1 & & 7,6 & 4,0 & 1,0 & 0,7 \\
\hline 2 & & 7,0 & 4,0 & 8,6 & 5,2 \\
\hline 3 & 13,3 & 11,5 & 2,0 & 8,6 & 9,8 \\
\hline 4 & 20,0 & 14,6 & 14,0 & 10,1 & 12,4 \\
\hline 5 & 20,0 & 16,6 & 16,0 & 18,2 & 12,4 \\
\hline 6 & 13,3 & 17,8 & 24,0 & 17,2 & 16,3 \\
\hline 7 & 6,7 & 15,3 & 12,0 & 18,2 & 21,6 \\
\hline 8 & 26,7 & 5,7 & 22,0 & 13,6 & 20,9 \\
\hline Total & 100,0 & 100,0 & 100,0 & 100,0 & 100,0 \\
& $N=15$ & $N=157$ & $N=50$ & $N=198$ & $N=153$ \\
\hline
\end{tabular}

Fonte: Pesquisa Relações Raciais no Rio de Janeiro - CEAP-DATAUFF, 2000.

Tabela 5

Índice de percepção do racismo, segundo a cor (alta, média, baixa)

\begin{tabular}{c|c|c|c|c|c}
\hline $\begin{array}{c}\text { Índice de percepção de } \\
\text { preconceito }\end{array}$ & Amarelo & Branco & Pardo & Preto & Indígena \\
\hline Alta (6-8) & 46,7 & 38,8 & 49,0 & 58,8 & 58,0 \\
\hline Média (3-5) & 53,3 & 42,7 & 36,9 & 34,6 & 32,0 \\
\hline Baixa (0-2) & - & 18,4 & 14,1 & 6,6 & 10,0 \\
\hline Total & 100,0 & 100,0 & 100,0 & 100,0 & 100,0 \\
\hline
\end{tabular}

Fonte: Pesquisa Relações Raciais no Rio de Janeiro - CEAP- DATAUFF, 2000.

Tabela 6

Índice de percepção do racismo, segundo o gênero (\%)

\begin{tabular}{c|c|c}
\hline $\begin{array}{c}\text { Índice de percepção do } \\
\text { preconceito }\end{array}$ & Masculino & Feminino \\
\hline 0 & 2,7 & 3,0 \\
\hline 1 & 3,9 & 2,5 \\
\hline 2 & 7,4 & 3,5 \\
\hline 3 & 11,7 & 7,6 \\
\hline 4 & 13,1 & 12,1 \\
\hline 5 & 16,6 & 16,4 \\
\hline 6 & 18,2 & 19,5 \\
\hline 7 & 15,4 & 20,7 \\
\hline 8 & 11,0 & 14,7 \\
\hline Total & 100,0 & 100,0 \\
& $N=565$ & $N=605$ \\
\hline
\end{tabular}

Fonte: Pesquisa Relações Raciais no Rio de Janeiro - CEAP- DATAUFF, 2000. 
contribua para que entre as mulheres o racismo seja percebido com mais intensidade do que entre os homens. ${ }^{10}$

Tabela 7

Índice de percepção do racismo, segundo o gênero

(alta, média e baixa)

\begin{tabular}{c|c|c}
\hline Índice de percepção do preconceito & Masculino & Feminino \\
\hline Alta (6-8) & 44,6 & 54,8 \\
\hline Média (3-5) & 41,4 & 36,1 \\
\hline Baixa (0-2) & 14,0 & 9,0 \\
\hline Total & 100,0 & 100,0 \\
\hline
\end{tabular}

Fonte: Pesquisa Relações Raciais no Rio de Janeiro - CEAP-DATAUFF, 2000.

Observando-se as Tabelas 8 e 9 é possível afirmar que se mantém uma relação direta entre instruçãa formal e percepção do racismo, com exceção do subgrupo que tem curso Superior completo. Isto fica mais evidente quando se considera aqueles que demonstram baixa percepção do racismo: entre os analfabetos, a proporção é de $18 \%$ e cai para $10,9 \%$ entre aqueles com $1^{\circ}$ Grau incompleto, para $8 \%$ entre aqueles com $2^{\circ}$ Grau incompleto e para $7,7 \%$ entre aqueles com Superior incompleto; então, a proporção se eleva para $20 \%$ entre aqueles que têm curso Superior completo. Surpreendentemente, observa-se que os indivíduos sem instrução e os indivíduos com instrução superior apresentam padrões semelhantes de distribuição no índice de percepção do racismo. ${ }^{11}$

Tabela 8

Índice de percepção do racismo, segundo o grau de escolaridade

(\%)

\begin{tabular}{c|c|c|c|c|c}
\hline $\begin{array}{c}\text { Índice de } \\
\text { percepção do } \\
\text { preconceito }\end{array}$ & $\begin{array}{c}\text { Analfabeto/ } \\
\text { primário } \\
\text { incompleto }\end{array}$ & $\begin{array}{c}\text { Primário/ } \\
1^{\circ} \text { grau } \\
\text { incompleto }\end{array}$ & $\begin{array}{c}1^{\circ} \text { grau/ } \\
2^{\circ} \text { grau } \\
\text { incompleto }\end{array}$ & $\begin{array}{c}2^{\circ} \text { grau/ } \\
\text { superior } \\
\text { incompleto }\end{array}$ & $\begin{array}{c}\text { Superior } \\
\text { completo }\end{array}$ \\
\hline 0 & 4,8 & 2,1 & 0,8 & 3,5 & 3,3 \\
\hline 1 & 4,4 & 5,0 & 2,0 & 0,7 & 5,0 \\
\hline 2 & 8,8 & 3,8 & 5,2 & 3,5 & 11,7 \\
\hline 3 & 11,6 & 8,8 & 10,8 & 8,8 & 6,7 \\
\hline 4 & 14,5 & 11,2 & 14,4 & 11,2 & 11,7 \\
\hline 5 & 15,4 & 19,7 & 13,3 & 16,1 & 18,3 \\
\hline 6 & 18,1 & 21,2 & 14,1 & 21,2 & 18,3 \\
\hline 7 & 15,4 & 18,2 & 22,1 & 18,2 & 10,0 \\
\hline 8 & 7,0 & 10,0 & 17,3 & 16,8 & 15,0 \\
\hline Total & 100,0 & 100,0 & 100,0 & 100,0 & 100,0 \\
& $N=227$ & $N=340$ & $N=249$ & $N=285$ & $N=60$ \\
\hline
\end{tabular}

Fonte: Pesquisa Relações Raciais no Rio de Janeiro - CEAP- DATAUFF, 2000. 


\section{Tabela 9}

Índice de percepção do racismo, segundo o grau de escolaridade (alta, média, baixa)

\begin{tabular}{c|c|c|c|c|c}
\hline $\begin{array}{c}\text { Índice de } \\
\text { percepção do } \\
\text { preconceito }\end{array}$ & $\begin{array}{c}\text { Analfabeto/ } \\
\text { primário } \\
\text { incompleto }\end{array}$ & $\begin{array}{c}\text { Primário / } 1^{\circ} \\
\text { incompleto }\end{array}$ & $\begin{array}{c}1^{\circ} \text { grau/2o } \\
\text { incompleto }\end{array}$ & $\begin{array}{c}2^{\circ} \text { grau/ } \\
\text { superior } \\
\text { incompleto }\end{array}$ & $\begin{array}{c}\text { Superior } \\
\text { completo }\end{array}$ \\
\hline Alto (6-8) & 40,5 & 49,4 & 53,5 & 56,2 & 43,3 \\
\hline Médio (3-5) & 41,5 & 39,7 & 38,5 & 36,1 & 36,7 \\
\hline Baixo (0-2) & 18,0 & 10,9 & 8,0 & 7,7 & 20,0 \\
\hline Total & 100,0 & 100,0 & 100,0 & 100,0 & 100,0 \\
\hline
\end{tabular}

Fonte: Pesquisa Relações Raciais no Rio de Janeiro - CEAP-DATAUFF, 2000.

Por fim, a idade também aparece como uma variável mediadora da percepção do racismo na população fluminense. As Tabelas 10 e 11 mostram que existe uma relação inversa entre idade e percepção do racismo. É provável que isto reflita o fato de que as gerações mais jovens estão sendo socializadas em ambientes mais democráticos, tendo acesso a um nível de escolaridade mais elevado e demonstrando menor tolerância à existência de relações desiguais que já estão cristalizadas na sociedade.

Tabela 10

Índice de percepção do racismo segundo idade (\%)

\begin{tabular}{c|c|c|c|c|c|c}
\hline $\begin{array}{c}\text { Índice de percepção } \\
\text { de preconceito }\end{array}$ & 18 a 24 & 25 a 34 & 35 a 44 & 45 a 54 & 55 a 59 & $\begin{array}{c}60 \text { ou } \\
\text { mais }\end{array}$ \\
\hline 0 & & 1,4 & 4,1 & 3,3 & 3,5 & 5,1 \\
\hline 1 & 2,0 & 2,1 & 2,7 & 3,9 & 4,8 & 5,7 \\
\hline 2 & 4,4 & 2,5 & 5,2 & 7,8 & 9,7 & 8,9 \\
\hline 3 & 11,2 & 9,0 & 9,5 & 9,4 & 4,8 & 12,1 \\
\hline 4 & 17,3 & 11,0 & 10,7 & 11,2 & 17,7 & 12,1 \\
\hline 5 & 10,1 & 20,3 & 17,2 & 17,2 & 9,7 & 18,5 \\
\hline 6 & 20,8 & 22,4 & 17,9 & 19,4 & 14,6 & 13,4 \\
\hline 7 & 16,8 & 23,5 & 15,5 & 17,2 & 17,7 & 15,9 \\
\hline 8 & 17,4 & 7,8 & 17,2 & 10,6 & 17,7 & 8,3 \\
\hline Total & 100,0 & 100,0 & 100,0 & 100,0 & 100,0 & 100,0 \\
& $N=197$ & $N=281$ & $N=296$ & $N=180$ & $N=62$ & $N=157$ \\
\hline
\end{tabular}

Fonte: Pesquisa Relações Raciais no Rio de Janeiro - CEAP-DATAUFF, 2000. 
Tabela 11

Índice de percepção do racismo, segundo a idade (alta, média, baixa)

\begin{tabular}{c|c|c|c|c|c|c}
\multicolumn{7}{c}{ (alta, média, baixa) } \\
\hline $\begin{array}{c}\text { Índice de percepção } \\
\text { de preconceito }\end{array}$ & 18 a 24 & 25 a 34 & 35 a 44 & 45 a 54 & 55 a 59 & $\begin{array}{c}60 \text { ou } \\
\text { mais }\end{array}$ \\
\hline Alto (6-8) & 55,0 & 53,7 & 50,6 & 47,2 & 50,0 & 37,6 \\
\hline Médio (3-5) & 38,6 & 40,3 & 37,4 & 37,8 & 32,2 & 42,7 \\
\hline Baixo (0-2) & 6,4 & 6,0 & 12,0 & 15,0 & 17,8 & 19,7 \\
\hline Total & 100,0 & 100,0 & 100,0 & 100,0 & 100,0 & 100,0 \\
\hline
\end{tabular}

Fonte: Pesquisa Relações Raciais no Rio de Janeiro - CEAP- DATAUFF, 2000.

\section{Conclusões}

Os resultados do survey realizado pelo CEAP-DATAUFF no Rio de Janeiro confirmam o que vem sendo apontado por outras pesquisas sobre atitudes raciais: os brasileiros se consideram isentos de preconceito racial, mas afirmam a existência de racismo na sociedade, entendido como preconceito e discriminação racial. Isso leva a crer que, tomando de empréstimo as palavras de Schwarcz, "todo brasileiro se sente como uma ilha de democracia racial, cercado de racistas por todos os lados" (1996:155). ${ }^{12}$ Se é verdade que continua a existir no Brasil esse "racismo indizível", isso coloca dificuldades tanto para a pesquisa científica quanto para a ação política e sugere que o mais urgente é entender os processos de estigmatização a que estão sujeitos os brasileiros de ascendência africana, processos estes que talvez não se deixem identificar facilmente através de entrevistas estruturadas e de questionários, que são os instrumentos mais largamente utilizados nos surveys atitudinais. Nesta direção, uma contribuição importante tem sido dada, por exemplo, pelos estudos realizados sobre o racismo nos meios de comunicação, pois nestes casos as fontes principais utilizadas não são os depoimentos individuais, mas sim os produtos veiculados nos meios de comunicação e que circulam no mercado editorial. Através destas formas de discurso (nem sempre verbal) a existência dos estereótipos negativos associados aos brasileiros que têm ascendência africana é facilmente comprovada, revelando algo que dificilmente aparece nos depoimentos e entrevistas (cf. Araújo, 2000).

Embora seja um fato sociologicamente importante que os brasileiros evitem expressar verbalmente o que entendem ser preconceito racial, o fato de que os brancos continuam tendo acesso 
privilegiado às oportunidades sociais convida à reflexão sobre os limites das concepçôes que vêem o racismo apenas como resultado de atitudes e atos individuais, sem atentar para a dinâmica estrutural que extrapola essa dimensão individual. Em termos de políticas, a questão que imediatamente se coloca é que embora seja necessário o compromisso individual com a recusa do preconceito e da discriminação esse compromisso não é suficiente para alterar a estrutura racialmente desigual da sociedade brasileira.

O fato de que os brasileiros neguem que sejam "racistas", e que mesmo os negros neguem que tenham sofrido discriminação racial, não é algo que pode ser considerado novo. A maior novidade é o reconhecimento público de que o racismo é um problema presente na sociedade brasileira, fato que, segundo Guimarães (1998), depende da interação de pelo menos três agentes principais: os movimentos sociais em prol da cidadania, o discurso dos intelectuais, principalmente os cientistas sociais, e a opinião pública internacional. As evidências de que a maioria da população brasileira, embora com graus diferenciados, percebe a existência do racismo suscita novas questôes no debate teórico sobre as atitudes raciais.

Nas definições que estão sendo popularizadas o racismo tem sido entendido como sinônimo de preconceito e discriminação, e não mais como sinônimo de segregação. Estamos diante, portanto, da percepção do "racismo de atitude", mas restaria analisar até que ponto há percepção do "racismo de sistema" (ou "racismo institucional”). Isso é muito importante tendo em vista que a mudança das atitudes individuais - no sentido de menor verbalização dos estereótipos negativos associados aos negros e de maior aceitação da proximidade social - não tem sido acompanhada da diminuição das desigualdades raciais que continuaram a crescer durante as décadas de 1980 e 1990 . Nesse novo contexto, é crucial que compreendamos melhor a relação existente entre as atitudes individuais e a dinâmica estrutural, evitando o reducionismo individualista ou estruturalista.

Acreditamos que os resultados da análise que apresentamos neste texto exemplificam bem algumas das dificuldades enfrentadas pelas pesquisas empíricas voltadas para a mensuração do preconceito ou discriminação raciais, que já têm sido destacadas por diversos autores (Elias, 2000; Goldberg, 1990). No entanto, acreditamos que outros temas permanecem pouco explorados nos estudos sobre o racismo no Brasil, como as explanações para as desigualdades, as preferências em termos de políticas raciais e as expla- 
nações para tais preferências. A pesquisa realizada pelo CEAP-DATAUFF avançou um pouco nesta direção ao incluir perguntas sobre o apoio a diferentes propostas de ação afirmativa. Isto é algo importante e reflete a ampliação do debate sobre o tema na sociedade, seja por iniciativa de organizações anti-racistas, de pesquisadores, ou de agências governamentais. ${ }^{13} \mathrm{Uma}$ análise preliminar revela que: i) ainda é grande o desconhecimento sobre as políticas de ação afirmativa; ii) e que entre aqueles que já ouviram falar do assunto, as opiniões estão divididas. A pesquisa CEAP-DATAUFF aponta que $60 \%$ dos entrevistados não tinham ouvido falar sobre os projetos que previam a reserva de vagas para os negros nas universidades e no mercado de trabalho, e que existe uma tendência de apoio às políticas que franqueiam o acesso de negros às universidades públicas e à participação em comerciais de TV - respectivamente 55,8\% e 63,8\%. Ao contrário do que se poderia esperar, não foi possível identificar uma correlação positiva entre percepção do racismo e apoio à implementação de políticas de ação afirmativa, fato que sugere a necessidade de investigar que outros fatores estariam influenciando as preferências dos entrevistados. 


\section{Anexo Metodológico}

A técnica escolhida para a análise dos dados foi a construção de duas escalas aditivas. Uma escala de preconceito racial e outra escala de percepção do racismo, de modo a medir melhor os dois termos de nosso paradoxo: a alta percepção de racismo na sociedade e a baixa admissão de preconceito individual. O primeiro passo na produção de qualquer escala é selecionar o conjunto de perguntas relacionadas à dimensão que se quer medir. Estas perguntas são então submetidas a algum processo de validação. Validação, neste contexto, se refere a uma preocupação metodológica com garantir que as nossas técnicas e instrumentos de pesquisa estejam realmente medindo o conceito teórico que desejamos medir.

Escolhemos a análise fatorial como técnica de validação de nossas escalas. A análise fatorial possui um tipo de teste de significância, que permite estabelecer o quanto e como o conjunto de variáveis selecionado está relacionado entre si. Ou seja, a análise fatorial mede o quanto um conjunto de variáveis varia junto, e se esta "covariância" - que é o termo estatístico correto - é devido a algum fator comum que rege o comportamento de cada variável ou se esta covariância pode ser atribuída simplesmente à variação aleatória nos dados. E este fator comum que a escala aditiva estaria medindo. É certamente uma atribuição arbitrária, a que nenhuma técnica de validação pode fugir, considerar que o fator estatístico encontrado mede o conceito teórico desejado. No entanto, se as perguntas forem bem formuladas e todas estiverem se referindo a dimensões de um único fenômeno teórico, a significância estatística nos dá maior segurança de que o conjunto das perguntas mede melhor o fenômeno em estudo do que cada pergunta isoladamente.

Deve-se esclarecer que a análise fatorial, neste uso, é em alguma medida um processo interativo em que o conjunto de variá- 
veis inicialmente selecionado vai sendo reduzido até que sobrevivam apenas as variáveis associadas a um único fator.

\section{Estatísticas básicas dos índices}

\begin{tabular}{l|c|c}
\hline & $\begin{array}{c}\text { Índice de percepção } \\
\text { de preconceito }\end{array}$ & Índice de preconceito \\
\hline $\mathrm{N}$ & 1171 & 1171 \\
Média & 5,19 &, 61 \\
Mediana & 5,00 &, 00 \\
Moda & 6 &, 00 \\
Desvio Padrão & 2,06 &, 97 \\
Percentis 25 & 4,00 &, 00 \\
50 & 5,00 &, 00 \\
75 & 7,00 & 1,00 \\
\hline
\end{tabular}

\section{Análise Fatorial}

\section{Índice de Preconceito Racial}

Total de variância explicada

\begin{tabular}{l|c|c|c|c|c|c|c}
\hline & & \multicolumn{3}{|c|}{ Initial eigenvalues } & \multicolumn{3}{c}{$\begin{array}{c}\text { Extraction sums of squared } \\
\text { loadings }\end{array}$} \\
\hline & & Total & $\begin{array}{c}\% \text { of } \\
\text { Variance }\end{array}$ & $\begin{array}{c}\text { Cumulative } \\
\%\end{array}$ & Total & $\begin{array}{c}\% \text { of } \\
\text { Variance }\end{array}$ & $\begin{array}{c}\text { Cumulative } \\
\%\end{array}$ \\
\hline Component & 1 & 1,805 & 30,079 & 30,079 & 1,805 & 30,079 & 30,079 \\
\hline & 2 &, 976 & 16,262 & 46,341 & & & \\
\hline & 3 &, 941 & 15,676 & 62,017 & & & \\
\hline & 4 &, 839 & 13,979 & 75,996 & & & \\
\hline & 5 &, 803 & 13,382 & 89,378 & & & \\
\hline & 6 &, 637 & 10,622 & 100,000 & & & \\
\hline
\end{tabular}

Extraction method: Principal component analysis.

Component Matrix

\begin{tabular}{c|c}
\hline & Component 1 \\
P.56.3X &, 705 \\
P.18.BX &, 626 \\
P.56.1X &, 613 \\
P.48PREC &, 518 \\
P.32X &, 369 \\
P.58X &, 369 \\
\hline
\end{tabular}




\section{Índice de Percepção de Preconceito Racial}

Total Variance Explained

\begin{tabular}{l|c|c|c|c|c|c|c}
\hline & & \multicolumn{3}{|c|}{ Initial eigenvalues } & \multicolumn{3}{c}{$\begin{array}{c}\text { Extraction sums of squared } \\
\text { loadings }\end{array}$} \\
\hline & & Total & $\begin{array}{c}\% \text { of } \\
\text { Variance }\end{array}$ & $\begin{array}{c}\text { Cumulati } \\
\text { ve \% }\end{array}$ & Total & $\begin{array}{c}\% \text { of } \\
\text { Variance }\end{array}$ & $\begin{array}{c}\text { Cumulati } \\
\text { ve \% }\end{array}$ \\
\hline Component & 1 & 2,380 & 29,745 & 29,745 & 2,380 & 29,745 & 29,745 \\
\hline & 2 &, 989 & 12,364 & 42,109 & & & \\
\hline & 3 &, 912 & 11,394 & 53,503 & & & \\
\hline & 4 &, 883 & 11,044 & 64,547 & & & \\
\hline & 5 &, 802 & 10,019 & 74,566 & & & \\
\hline & 6 &, 727 & 9,090 & 83,656 & & & \\
\hline & 7 &, 677 & 8,466 & 92,122 & & & \\
\hline & 8 &, 630 & 7,878 & 100,000 & & & \\
\hline
\end{tabular}

Extraction method: Principal component analysis.

Component Matrix

\begin{tabular}{l|c}
\hline & Component 1 \\
\hline P.31X &, 602 \\
P.14X &, 574 \\
P.47.3X &, 559 \\
P.8.3X &, 557 \\
P.33X &, 546 \\
P.48PERC &, 537 \\
P.56.4X &, 520 \\
P.18.DX &, 456 \\
\hline
\end{tabular}

\section{Notas}

1. A pesquisa aplicou dois modelos de classificação de cor para identificar os entrevistados. O objetivo era, de um lado, investigar a política de identidade racial entre a população do Estado do Rio de Janeiro e, de outro lado, testar a acuidade da metodologia de classificação segundo cor e raça utilizada pelo Instituto Brasileiro de Geografia e Estatística - IBGE nos seus levantamentos censitários. No primeiro método, o entrevistador indicava a cor do entrevistado considerando a classificação do IBGE, cujas categorias são: branco, preto, pardo, amarelo e indígena. Neste levantamento contou-se: $42,8 \%$ de brancos, $40,4 \%$ de pardos, $16,2 \%$ de pretos, $0,5 \%$ de indígenas e $0,2 \%$ de amarelos. No segundo método, o próprio entrevistado foi solicitado a escolher uma das opções utilizadas pelo IBGE. Para fins de nossas análises neste trabalho utilizamos o segundo modelo, buscando, dessa forma, não somente evitar algum viés que porventura tivesse ocorrido na produção do dado por parte do entrevistador, mas objetivando trabalhar com evidências empíricas que permitissem comparações 


\section{Cloves Luiz Pereira Oliveira e Paula Cristina da Silva Barreto}

com outros estudos. A título de referência, segundo o Censo 2000, o Estado do Rio de Janeiro tem 14.391.282 habitantes. Entre os que responderam ao quesito "cor", $53,9 \%$ são brancos, $33,7 \%$ pardos, $10,9 \%$ pretos e menos de $1 \%$ amarelos e indígenas. A respeito do debate sobre as classificações da cor no Brasil, ver Piza (2000), Petruccelli (2002), Guimarães (1999), Sansone (1996) e Silva (1994).

2. Ver a esse respeito Nogueira (1942); Bicudo (1947); Willems (1949); Morse (1953); Bastide (1956); Bastide \& Fernandes (1959); Bastide \& Van den Berghe (1957); Cardoso \& Ianni (1960).

3. Essa pesquisa foi realizada como parte do ciclo de estudos da UNESCO, por Lucila Hermann, nos anos 1950. Foram aplicados questionários a uma amostra intencional formada por 580 estudantes "brancos", de cinco colégios de São Paulo.

4. Para atualizações em torno do tema da desigualdade racial ver Henriques (2001) e Silva (2000).

5. A literatura que trata dos estudos atitudinais discute a existência do "efeito da desejabilidade social”, que provoca um viés no sentido de favorecer a escolha das opções que indicam concordância com as normas socialmente aceitas. Alguns estudos experimentais têm mostrado que esse efeito é mais acentuado quando se trata de "temas sensíveis" (uso de drogas, AIDS, sexualidade, racismo etc.) e afeta especialmente o segmento da população que tem nível de escolaridade mais elevado (Dovidio \& Fazio, 1992).

6. Ver a este respeito Sears, Sidanius \& Bobo (2000); Schuman, Charlotte \& Bobo (1997) e Sigelman \& Welch (1991).

7. Visto por outro ângulo, isto quer dizer que $89,2 \%$ dos entrevistados afirmaram que nunca sofreram com o sexismo, $84 \%$ afirmaram que nunca se sentiram discriminados devido a fatores raciais e $69 \%$ afirmaram que jamais depararam com a discriminação de classe.

8. Tratando da percepção da discriminação racial, uma pesquisa de base amostral realizada em 1986, em São Paulo, mostrou que, apesar de no plano genérico, dos "direitos", se afirmar a existência da igualdade entre "negros" e "brancos", quando eram colocadas situações mais específicas, como o tratamento policial, havia reconhecimento da existência de discriminação racial. Este reconhecimento ocorria, independente da cor, e crescia com a renda e o grau de instrução (Hasenbalg \& Silva, 1993).

9. Ver, a respeito, Piza (2000).

10. Num estudo sobre o preconceito e a discriminação racial com base nas queixas de ofensas e tratamento desigual dos negros no Brasil, Guimarães notou que as mulheres eram mais queixosas que os homens, bem como que a discriminação racial tende a ocorrer "entre pessoas de status de classe assimétrico, ou ocupando posições assimétricas de poder" (Guimarães, 1998:57).

11. Esta aproximação também tem sido apontada em pesquisas sobre valores e atitudes políticas (Araújo et alii, 2000).

12. Em pesquisa realizada com estudantes universitários de São Paulo, Schwarcz chegou aos seguintes resultados: diante da pergunta "Você tem preconceito?" 97\% dos estudantes entrevistados respondeu "Não"; diante da pergunta "Você conhece alguém que tenha preconceito?" $98 \%$ respondeu "sim". Embora a pesquisa não permita saber de que maneira o preconceito racial foi definido pelos entrevistados, fica eviden- 
te que o racismo é visto sempre como algo que atinge o outro, e do qual o próprio indivíduo está livre.

13. Ver a esse respeito, Silva (2002), Moehlecke (2000), Fry (2000), Guimarães (1999), Reis (1997) e DaMatta (1997).

\section{Referências Bibliográficas}

ALMEIDA, Alberto Carlos; YOUNG, Clifford \& PINTO, Andréia Soares (2002). "Qual é a cor do brasileiro?". Insight. Inteligência, Ano V, no 17, pp. 31-39.

ARAÚJO, C. E. P.; SANTOS, E. G. C. \& COELHO, M. F. P. (orgs.) (2000). Política e valores. Brasília, Editora da UnB.

ARAÚJO, Joel Zito Almeida de (2000). A negação do Brasil: o negro na telenovela brasileira. São Paulo, Editora SENAC-São Paulo.

BARRETO, Paula Cristina da Silva (2003). Racismo e anti-racismo na perspectiva de estudantes universitários de São Paulo. Tese de Doutorado em Sociologia, São Paulo, Universidade de São Paulo, 272 p.

BASTIDE, Roger (1956). "Stereotypes et prejuge de couleur”. Sociologia. Revista Didática e Cientifica. Escola Livre de Sociologia e Política, vol. 18, no 2, pp. 141-171.

\& FERNANDES, Florestan (1959). Brancos e negros em São Paulo: ensaio sociológico sobre aspectos da formação, manifestações atuais e efeitos do preconceito de cor na sociedade paulistana. São Paulo, Cia. Editora Nacional, Coleção Brasiliana, vol. 305

_ \& e VAN DEN BERGHE, Pierre (1957). "Stereotypes, norms and interracial behavior in São Paulo, Brazil”. American Sociological Review, no 6, vol. 22, pp. 689-694.

BICUDO, Virginia Leone (1947). "Atitudes raciais de pretos e mulatos em São Paulo". Sociologia. Revista Didática e Científica. Escola Livre de Sociologia e Política, vol. 9, n 3, pp. 195-219.

CARDOSO, Fernando H. \& IANNI, Octávio (1960). Cor e mobilidade social em Florianópolis. Aspectos das relaçôes entre negros e brancos numa comunidade do Brasil Meridional. São Paulo, Companhia Editora Nacional, Coleção Brasiliana, vol. 307.

DAMATTA, Roberto (1997). "Notas sobre o racismo à brasileira”. In J. Souza (ed.), Multiculturalismo e racismo: uma comparação Brasil-Estados Unidos. Editora Paralelo 15, pp. 69-74.

DOVIDIO, J. F. \& FAZIO, R. H. (1992). "New technologies for the direct and indirect assessment of attitudes". In J. M. Tanur (ed.), Questions about questions. Inquiries into the cognitive bases of surveys. New York, Russell Sage Foundation.

ELIAS, Norbert \& SCOTSON, John (2000). Os estabelecidos e os outsiders. Rio de Janeiro, Zahar.

FERNANDES, Florestan (1972). O negro no mundo dos brancos. São Paulo, Difel.

FRY, Peter (2000). "Politics, nationality, and the meanings of 'race' in Brazil". In Brazil. Burdens of the Past. Promises of the Future. Daedalus. Journal of the American Academy of Arts and Sciences, vol.129, no 2, pp. 83-118.

GOLDBERG, David Theo (1990). The anatomy of racism. Minneapolis, University of Minnesota Press.

GUIMARÃES, Antônio Sérgio A. (1999). Racismo e anti-racismo no Brasil. São Paulo, FUSP/Editora 34. 


\section{Cloves Luiz Pereira Oliveira e Paula Cristina da Silva Barreto}

(1998). Preconceito e discriminação: Queixas de ofensas e tratamento desigual dos negros no Brasil. Publicação do Programa A Cor da Bahia/ Mestrado em Sociologia da Faculdade de Filosofia e Ciências Humanas da UFBa, no 3. Salvador: Novos Toques.

HASENBALG, Carlos \& SILVA, Nelson do Valle (1993). "Notas sobre desigualdade racial e política no Brasil”. Estudos Afro-Asiáticos, no 25, pp. 141-159.

HENRIQUES, Ricardo (2001). "Desigualdade racial no Brasil: evolução das condições na década de 90”. Texto para discussão 807, Brasília, IPEA.

JONES, James (1973). Racismo e preconceito. São Paulo, Universidade de São Paulo.

MOEHLECKE, Sabrina (2000). Propostas de ações afirmativas no Brasil. O acesso da população negra ao ensino superior. Dissertação de mestrado em Educação apresentada à Faculdade de Educação de São Paulo.

MORSE, R. M. (1953). “The negro in São Paulo, Brazil”. Journal of Negro History, vol. 3, no 38, pp. 290-306.

NOGUEIRA, Oracy (1942). “Atitude desfavorável de alguns anunciantes de São Paulo em relação aos empregados de cor”. Sociologia. Revista Didática e Científica. Escola Livre de Sociologia e Política, vol. 4, no 4, pp. 328-358.

_ (1998). Preconceito de marca: Relaçôes raciais em Itapetininga. São Paulo, Editora da Universidade de São Paulo.

PETRUCCELLI, José Luís (2002). A declaração de cor/raça no Censo 2000: um estudo comparativo. Rio de Janeiro, IBGE.

PIZA, Edith (2000). "Branco no Brasil? Ninguém sabe, ninguém viu”. In A. S. A. Guimarães \& L. Hunttley (orgs.), Tirando a máscara: ensaios sobre o racismo no Brasil. Rio de Janeiro, Editora Paz e Terra, pp. 97-125.

REIS, Fábio Wanderley (1997). "Mito e valor da democracia racial”. In J. Souza (ed.), Multiculturalismo e racismo: uma comparação Brasil-Estados Unidos. Editora Paralelo 15 , pp. 221-232.

SANSONE, Livio (1996). "Nem somente preto ou negro: o sistema de classificação racial no Brasil que muda”. Afro-Ásia, no 18, pp 165-187.

SCHUMAN, Howard; STEEH, Charlotte; BOBO, Lawrence \& KRYSAN, Maria (1997). Racial attitudes in America. Trends and interpretations. (edição revista). Cambridge, Harvard University Press.

SCHWARCZ, Lilia Moritz (1996). "Questão racial no Brasil”. In L. M. Schwarcz e L. V. Reis (orgs.), Negras imagens. São Paulo, EDUSP, pp. 153-177.

SEARS, David O.; SIDANIUS, Jim \& BOBO, Lawrence (eds.) (2000). Racialized politics. The debate about racism in America. Chicago, The University of Chicago Press.

SIGELMAN, L. \& WELCH, S. (1991). Black American views of racial inequality. The dream deferred. Cambridge, Cambridge University Press.

SILVA, Maria Aparecida da (2002). "Ações afirmativas em educação: acesso, permanência e sucesso do povo negro na universidade". Palmares em Ação, Ano I, no 2, pp.27-29.

SILVA, Nelson do Valle (2000). "Extensão e natureza das desigualdades raciais no Brasil”. In A. S. A. Guimarães \& L. Hunttley (orgs.), Tirando a máscara: ensaios sobre o racismo no Brasil. Rio de Janeiro, Editora Paz e Terra, pp. 33-51. 
(1994). "Uma nota sobre 'raça social' no Brasil". Estudos Afro-Asiáticos, no 26, pp. 67-80.

TURRA, C. \& VENTURI, G. (eds.) (1995). Racismo cordial: A mais completa análise sobre o preconceito de cor no Brasil. São Paulo, Ed. Ática.

TWINE, France Winddance (1998). Racism in a racial democracy. The maintenance of white supremacy in Brazil. Rutgers University Press.

WILLEMS, Emilio (1949). "Racial attitudes in Brazil”. American Journal of Sociology, no 54, pp. 402-8. 